\title{
Re-employment of Ex-offenders in China: Research on Employment Discrimination and the System of Elimination of Criminal Record
}

\author{
Yuting $\mathrm{Bu}^{1, *}$ \\ ${ }^{1}$ Lingnan University, BA of Global Liberal Arts \\ *Email: yutingbu@ln.hk
}

\begin{abstract}
The research on employment discrimination problems faced by ex-offenders in China is scarce. Due to this situation, this article explores the necessity of solving the stigma faced by ex-offender employment by using subjective evaluation questionnaire. The questionnaire collects ex-offenders' needs for equal employment and views on the System of Elimination of Criminal record. The results of the questionnaire show that $61 \%$ of people do not have reemployment problems caused by criminal records. More than $90 \%$ of people believe that the System of Elimination of Criminal record will play a positive role in equal employment for former offenders. Although this research cannot provide specific measures for China to solve the stigma faced by ex-offenders in employment, it can provide a general idea. In the long run, continuing to study this issue will help alleviate the employment problem of ex-offenders.
\end{abstract}

Keywords: Ex-offender, Criminal record, Re-employment, Social stigma.

\section{INTRODUCTION}

It is a global situation that people with critical records are hard to be employed. A survey by Holzer et al. showed that only about $40 \%$ of employers will "absolutely" or "probably" hire applicants with criminal records [1]. Scholars agree that after criminals have completed their sentences, stigmatization procedures must be restricted in order to let them successfully reintegrate into society $[2,3]$. Thus, exploring how to reduce the stigma ex-offenders faced in employment is of great social significance.

Nowadays, many studies have focused on comparative analysis of the policies about weakening the stigma of ex-offender. To begin with, the research of Doleac and Hansen found that "BTB policies (of the United States) decrease the probability of employment by 3.4 percentage points $(5.1 \%)$ for young, low-skilled black men [4]." Besides, Kurtovic and Rovira constructed a comparative model, which mentioned three levels of employment stigma affecting exoffenders [5]. For example, in Spain, employers have the possibility to ask employees to submit an extract of their criminal record, which is stigma at the macro-level [6]. In addition, Selbin et al. mentioned that interventions to clear records had a meaningful impact on the outcome of people with criminal records [7]. In the years after the intervention, the employment rate of ex-offenders (the percentage of participants with positive earnings) increased from approximately 75 percent to 80-85 percent. The macro-level observations show that in the Western countries, ex-offenders face a serious problem of employment discrimination.

In China, the employment discrimination of adult ex-offenders is also very serious, but the Chinese government and Chinese academia seem to have not realized the problem and the necessity of solving it. China implements a policy of issuing a criminal record certificate to applicants. Wang Bin argues that this is an over-term and over-range policy that will result in serious occupational segregation [8]. China's "Employment Services and Employment Management Regulations" specifically mentions the need to ensure equal employment for women, the disabled, people from ethnic minorities, and carriers of infectious diseases in response to employment discrimination. However, it does not involve the employment discrimination that exprisoners suffer. In addition, the "Labor Service Contract Law" stipulates that "the employer has the right to know the basic information directly related to the worker and the labor contract, and the worker should truthfully illustrate it." The employment discrimination 
that Chinese ex-offenders face is a typical structural stigma. Such an important sub-system of our society, that lacks clear and corresponding policies to help people with criminal records get a fair employment environment, is worthy of reflection.

Most of the foreign research studies measures to solve ox-offender employment discrimination from the perspective of structural stigma. However, compared with Western countries, China's cultural and social environment is likely to cause differences in the needs of ex-offenders or hinder the implementation of related policies. Therefore, this study explored the reemployment needs of ex-offenders and research their views on the system of elimination of criminal record in solving the employment discrimination problem of adult ex-offenders in China. The questionnaire is distributed to the ex-offenders through the community to understand their thoughts and needs. Through this research, more people will realize the importance of solving the stigma faced by ex-offenders. At the same time, this research provides new ideas for eliminating employment discrimination in ex-offender groups.

\section{METHODOLOGY}

\subsection{Research Method:}

Quantitative research method measured by questionnaire of subjective evaluation is applied in order to investigate the proportion of people facing employment problems and those who have different opinions on the "System of Elimination of Criminal record".

\subsection{Procedure:}

An online questionnaire survey contacted the staff of 30 community centers in 6 cities of different levels in China is sent to the adult residents with a history of conviction in the community. All the responses received within 15 days are collected for further analysis.

\subsection{Participants:}

There are 387 participants in total. All participants are ex-offenders aged 18 to 60 . They are selected from 30 community centers in 6 cities of different levels in China. They were informed that the survey is anonymous and their information will not be transferred to other uses in addition to completing this research.

\subsection{Analytical Plan:}

In statistics, independent variables are all categorical variables; dependent variable is the number of people who choose a certain option. The proportion of people who hold different views or have different experiences is counted for further discussion.

\section{RESULTS}

Many positions in China have clear requirements for academic qualifications when recruiting. The minimum requirement for academic qualifications in the recruitment requirements for national public officials is Junior College Diploma. Private companies have varying requirements for academic qualifications, which depends on the size of the company, salary levels, job characteristics, etc. For those with a high school degree or below, they are very uncompetitive in China's current job market.

HIGHEST EDUCATION LEVEL

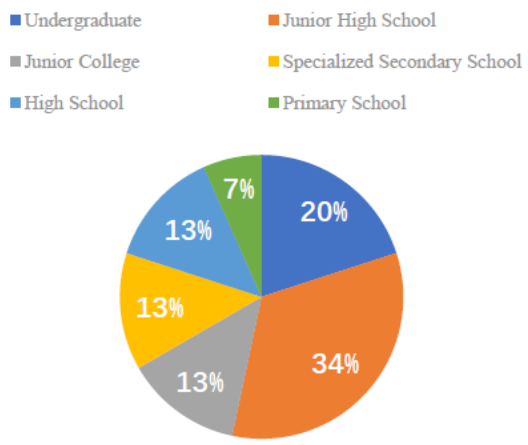

Figure 1 Ex-offenders' highest education level

In order to explore whether the problem of employment discrimination by former offenders is universal, the ex-offenders reported whether they encountered employment discrimination. People who suffer from employment discrimination account for a large proportion. Some people are not suitable for this survey because they have their own business.

$$
\text { Whether encounter employment discrimination }
$$$$
\text { after being released }
$$

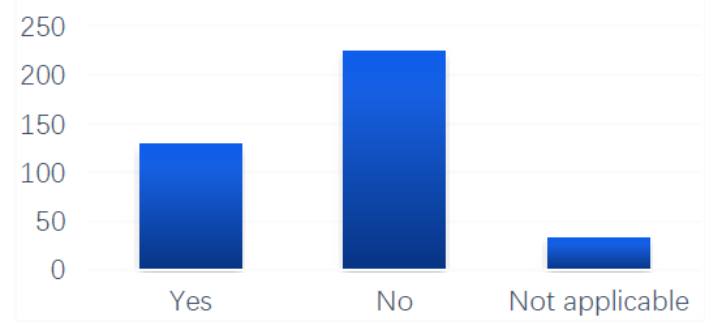

Figure 2 The situation of ex-offender encountered employment discrimination when re-employed

The ex-offenders agree on whether the government should intervene in employment. 


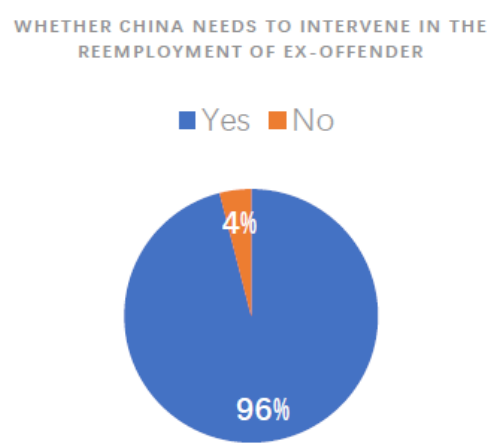

Figure 3 Participants opinion on whether China needs to intervene in the reemployment of ex-offender

We should consider whether this policy can be effective. Regarding the effect of the policy, most interviewees held a positive attitude. However, $1 \%$ of people still disagree with the effect of the policy.

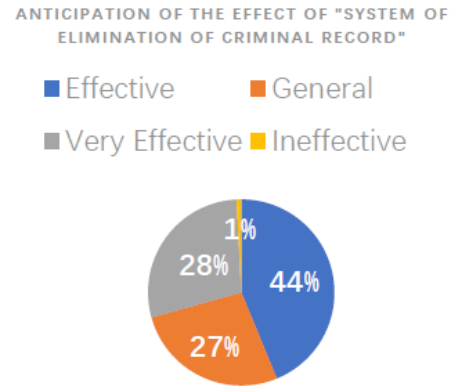

Figure 4 Participants' views on the effectiveness of the "System of Elimination of Criminal record"

The implementation of "System of Elimination of Criminal record" in China will be a brand new challenge. Since there is no suitable foreshadowing and excessive, we need to discuss whether this policy can conform to China's national conditions. Some people are negative or skeptical about the promotion and feasibility of the policy.

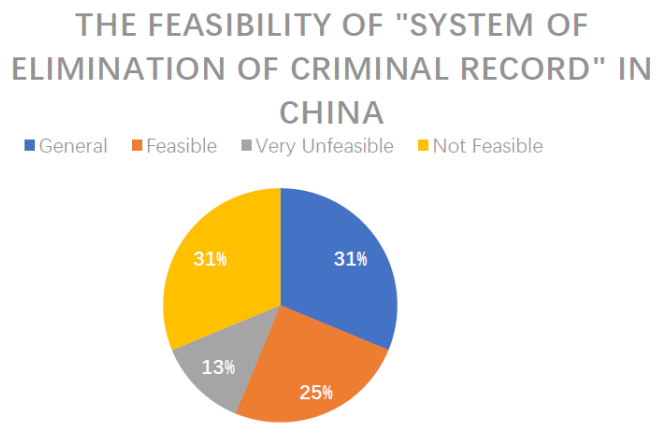

Figure 5 Participants' views on the feasibility of the "System of Elimination of Criminal record"
The implementation of "System of Elimination of Criminal record" in China will be a brand new challenge. Since there is no suitable foreshadowing and excessive, we need to discuss whether this policy can conform to China's national conditions. Some people are negative or skeptical about the promotion and feasibility of the policy.

\section{DISCUSSION}

One of the key points of this survey is to explore whether ex-offenders need to be intervened in employment. Figure 1 shows that most ex-offenders have low academic qualifications, and less than $20 \%$ of them have a bachelor degree or above. These people usually do not have a stable job before committing the crime. After being released from prison, they do not have a strong need for a stable job. Among the participants, about a quarter of them were self-employed after they were released from prison, while a third of them were engaged in unemployed jobs. Most of these people are not required to provide a certificate of no criminal record when starting a business or getting a job. Therefore, employment discrimination problems caused by criminal records mainly appear on people who want to work in stable jobs in units with authorized strength after they are released from prison. One-third of people report that they have encountered employment discrimination issues when they are trying to find a stable job. So we really need to pay attention to the employment issue of ex-offenders. $96 \%$ of participants believe that the Chinese government should intervene in the re-employment of suspects, even though some of these people have not experienced employment discrimination. They are obviously aware of the prevalence of employment discrimination in the exoffender group and the need to make changes, and eagerly hope that this situation can be improved.

The result also casts doubt upon whether the "System of Elimination of Criminal record" is feasible and effective. In terms of effect, $72 \%$ of participants predict that this policy will have a significant effect after implementation. Elimination of criminal records basically means that the work unit's access to the criminal record of the employed person is fundamentally cut off, unless they learn about it through news, rumors, etc. Criminal records will not be considered when screening candidates.

It is obviously not realistic to completely eliminate all criminal records. Respondents are not optimistic about the feasibility of the policy. It can be seen from Figure 5 that $31 \%$ of the reporters think this policy is not feasible, and 13 people think it is very unfeasible. Only $25 \%$ think that the "Elimination of Criminal Record" can be successfully implemented in China. The reason why people are not optimistic about this policy is determined by the current state and social environment. 
At present, some key national departments are gradually strengthening the control and requirements of the criminal record of the applicants when recruiting. For example, on April 7, 2021, the Ministry of Education publicly solicited citizens' opinions on the "Provisions on the Protection of Schools for Minors (Draft for Comment)." One of the draft opinions stipulates that schools should strictly implement the entry condition and admission inquiry system. Among them, it is clearly required that all persons who are applying for faculty, volunteers, social workers and other relevant minors' worked on- and off-campus should truthfully report whether there are illegal or criminal acts and submit the letter of commitment. Some invisible or incomplete requirements in the past will soon become clear regulations. Hidden employment discrimination is about to escalate into a serious and stubborn structural stigma.

For the government and the majority of the public, they prefer the restrictions with previous records when recruiting in key state institutions such as schools. They believe that such measures will help protect the campus or community environment, thereby giving the public the best protection. Therefore, under the relevant comment report, many expressed strong support for the policy of considering criminal records in employment. By considering the safety of the community and the students in the school in priority, they did not pay as much attention to the legitimate rights and interests of ex-offender which is also an inseparable member of society. While these measures protect the safety of other citizens, they also undermine the human rights of former offenders. However, the concerns of the government and the masses are also reasonable. Ex-offender could be a factor of social instability. Formal punishment may only allow them to receive the punishment they deserve, but it does not eliminate the possibility of committing a crime again. If the criminal record of previous offenders is completely eliminated, it is very likely that other social people, especially minors and other vulnerable groups, will be put at risk.

Therefore, the practice of completely eliminating criminal records is a bit extreme, but measures must also be taken to protect the rights of ex-offenders, and the problem of employment discrimination must not be aggravated. The methods that can be considered are to eliminate the criminal records of some criminals, while keeping some specific criminal records with a higher risk of re-offending. Except for key national units, employers are restricted from viewing employees' criminal records. Public security organs no longer provide certificates of no criminal record, etc. The state needs to make a good balance between the safety of its citizens and the human rights of former offenders.

\section{CONCLUSION}

This paper investigates the employment discrimination of ex-offenders and their views on the System of Elimination of Criminal record, although some people do not face the problem of employment discrimination because they are engaged in selfemployed or unemployed occupations. However, participants generally believe that the state should intervene in the employment of ex-offenders. Most people believe that once the System of Elimination of Criminal Record is implemented, it will solve the problem of ex-offender employment discrimination to a large extent. But now with the country strengthening the control of people with criminal convictions, the implementation of this policy is facing huge challenges. As the risks after the implementation of the policy are difficult to control, it is difficult for China to fully implement the system of elimination of criminal record. The feasibility of this policy has become a major problem. At present, the government and scholars should further study feasible policies, and implement certain restrictions and improvements on the System of Elimination of Criminal record to seek a balance between social security and ex-offender human rights.

\section{REFERENCES}

[1] Holzer, H.J. (2007). Collateral costs: The effects of incarceration on the employment and earnings of young workers. IZA Discussion Paper No. 3118.

[2] LeBel, TP (2012) Invisible stripes? Formerly incarcerated persons' perceptions of stigma. Deviant Behavior 33(2): 89-107.

[3] Murphy, D, Fuleihan, B, Richards, S, Jones, R (2011). The electronic 'scarlet letter': Criminal backgrounding and a perpetual spoiled identity. Journal of Offender Rehabilitation 50(3): 101-118.

[4] Doleac, Jennifer L, \& Hansen, Benjamin. (2020). The Unintended Consequences of "Ban the Box": Statistical Discrimination and Employment Outcomes When Criminal Histories Are Hidden. Journal of Labor Economics, 38(2), 321-374

[5] Kurtovic, Elina, \& Rovira, Marti. (2017). Contrast between Spain and the Netherlands in the hidden obstacles to re-entry into the labour market due to a criminal record. European Journal of Criminology, 14(5), 505-521.

[6] Larrauri, E, Jacobs, JB (2013) A Spanish window on European law and policy on employment discrimination based on criminal record. In: Daems, T, Snacken, S, van Zyl Smit, D (eds) European Penology? Oxford: Hart, 293-310. 
[7] Selbin, J, Mccrary, J, \& Epstein, J. (2018). UNMARKED? CRIMINAL RECORD CLEARING AND EMPLOYMENT OUTCOMES. The Journal of Criminal Law and Criminology (1973-), 108(1), 1-72.

[8] Wang, B. (2015). Problems in China's Criminal Record Verification System and Suggestions for Improvement. Anti-discrimination Law Review $2015,(00), 21-32$ 